parts have all come under fire in times of revolutionary change such as the early decades of the twentieth century.

Syntax, semantics and phonology deal, respectively, with the forms of utterances, their meanings and their realization in speech or writing. In traditional music, note order is as crucial as word order is in English. When we listen to a tune, our expectations and their satisfaction are governed by syntactic considerations, although we may not know what they are.

The psychological reality of musical syntax is demonstrated by our ability to identify wrong notes in music we have never heard before. Its value to the listener lies in establishing the tensions and resolutions that could never arise if the unfolding of the music were totally unpredictable - or totally predictable.

The semantics of music is something of a disaster area (but so, for that matter, is natural language semantics). Although a pastoral theme may well suggest the countryside, it cannot possibly assert that you are about to tread in a cowpat. But a ray of hope illuminates the attempt to assign meanings to vocal compositions, where the words and the music may be expected to tell the same story.

Swain invokes this principle to explain the dramatic effect of the chorus "For unto us a Son is born" in Handel's Messiah; but he could have done without it in discussing the music of the preceding aria, "The people that walked in darkness", where a lonely melodic line wanders about unpredictably in a minor key.

The phonology of a musical language is properly concerned with the conceptual (phonemic) relations between the notes rather than their acoustic (phonetic) realization. The tonal relations of Western classical music, so economically represented by stave notation, remained basically unchanged during the seventeenth, eighteenth and nineteenth centuries.

The real revolution wrought by the serialists at the beginning of the twentieth century was not to declare all the notes of the keyboard equal, but to throw out the conceptual distinction between homophonic intervals such as the major third and the diminished fourth, along with the bath water of decadent romanticism. But not for long: experiments by Jamshed Barucha have shown that the tonal baby has a way of crawling back into the musical reflexes of even quite fluent modernistic composers.

To illustrate his ideas, Swain discusses in detail such landmark compositions as Palestrina's "Sicut Cervis" and Beethoven's "Violin Concerto". But of more consequence for general musicology are his observations on musical evolution, artificial languages and the supporting role of musical communities. If he is right, the artistic health of languages such as jazz and rock seems assured; the music of small minorities, such as soli- tary composers of electronic music, faces bleaker prospects.

The least convincing chapter is that on musical metaphor. Perhaps the next edition will replace it by one on prosody, a common concern of poets and songwriters.

Musical Languages is an untidy, enthusiastic, perceptive book, to be heartily recommended to all thoughtful musicians.

Christopher Longuet-Higgins is in the Department of Experimental Psychology,

University of Sussex, Brighton BN1 9QG, UK.

\section{Born to science}

\section{Words, Thoughts and Theories}

by Alison Gopnik and Andrew N. Meltzoff

MIT Press: 1997. Pp. 268. \$30, £25.50

\section{Peter Bryant}

Anyone who has had any prolonged contact with children knows that their intellectual effectiveness changes remarkably as they grow older. This was first systematically demonstrated by Binet's intelligence test which showed ordinary children fumbling hopelessly with elementary verbal or spatial problems one year and solving them unhesitatingly the next. Later, many developmental psychologists, most notably Piaget, charted the details, many still controversial, of the kinds of problems young children can and cannot solve and how children get better at finding solutions as they grow older.

Intelligence testers, Piaget and most other developmental psychologists demonstrated that these changes tend to tail off around late adolescence (although they agreed that there is room for slight improvement during early adulthood) and they assumed that this endpoint in intellectual development is an intellectual summit. Until a child gets there, he or she is intellectually incomplete: after reaching the sum-

\section{New in paperback}

\section{Emotional Intelligence: Why It Can} Matter More Than IQ

by Daniel Goleman

Bantam, $\$ 13.95$

"Goleman has written an interesting if somewhat naive book. ...Some will find the journalistic tone repugnant, but anyone interested in emotion is likely to discover challenging new ideas in this book: it should be read by social workers and agony aunts everywhere." Stuart Sutherland, Nature 379, 34 (1996).

\section{The Power to Harm: Mind, Medicine} and Murder on Trial

by John Cornwell

Penguin, £7.99

In 1989, Joseph Wesbecker shot 20 of his former

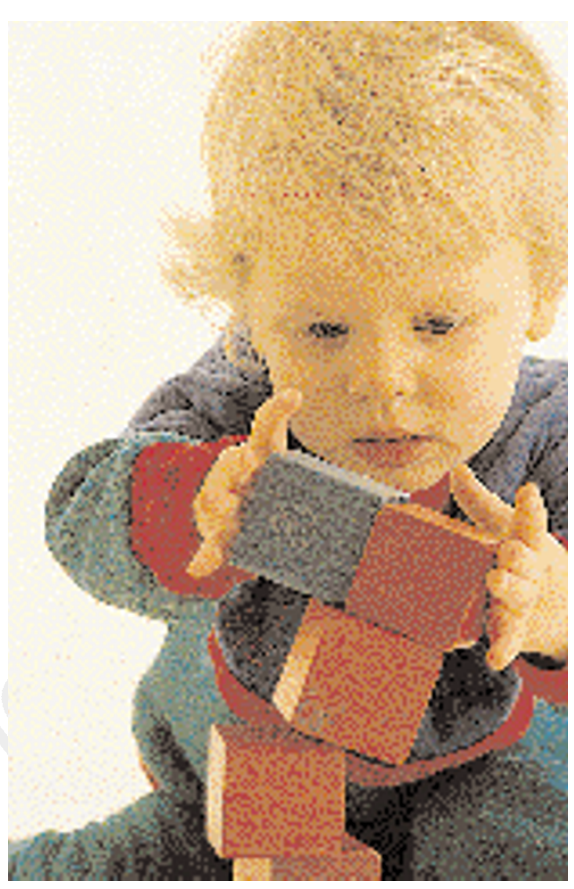

Early learning: scientific reasoning starts young, say Gopnik and Meltzoff.

mit, there will be no further improvements in intellectual machinery.

Psychologists vary greatly in how they characterize this endpoint, but Piaget's view probably remains the most influential. He claimed that the climax of intellectual change was scientific thinking: when children can form hypotheses, and test them systematically by looking at the effects of one variable at a time while holding the rest constant, they have reached the endpoint.

In their stimulating and well-written book, Alison Gopnik and Andrew N. Meltzoff attempt to overturn these usually unquestioned assumptions about the developmental endpoint and the late arrival of scientific reasoning.

Their main idea is that scientific reasoning is the cause, not the product, of chil-

colleagues and then himself. He had been on Prozac, and his victims and their families sued its makers, Eli Lilly, for compensation. Cornwell uses the trial to warn of the potential apocalypse created by "the growing crisis over reductionist solutions to individual suffering and social disorder". Reviewed by Keri K. Gould in Nature 383, 783 (1996).

Reality Rules: Picturing the World in Mathematics. Vol.1-The Fundamentals. Vol. 2 - The Frontier by John L. Casti

Wiley, each \$32.50, £19.99

"Casti Tours offers the most spectacular vistas of modern applied mathematics." Karl Sigmund, Nature 362, 669 (1993). 
dren's intellectual development. Children test hypotheses about the physical and social world around them from the time they are born, and form new hypotheses when the old ones prove unsatisfactory. They do so exactly like scientists, according to Gopnik and Meltzoff.

In particular, the authors claim that the hypotheses children entertain are always falsifiable and that children treat them as such. Like good scientists, children recognize when one of their ideas has not worked out and they look for a new and better one.

And the endpoint? Well, all that happens is that after a while people get tired of the whole process and are content to stick with the hypotheses they happen to have reached by then. So the authors contend that adulthood is the end, not the beginning, of scientific reasoning for most people.

This argument goes flat against the idea of development as a series of changes from an immature to a more-or-less complete system. On the contrary, the authors argue that the child's intellectual machinery undergoes no change at all. The process of testing and forming new hypotheses is the same in adolescence as in the first few days of life.

The child's hypotheses get closer to the truth as time goes by and the result is that the child's knowledge about the world keeps on growing. But the intellectual machinery that leads to this growth is always the same, until it burns out in early adulthood.

The book deals mainly with children up to the age of two years and is mostly concerned with their understanding of physical objects and social interactions. There are sections on children's success in solving simple means-ends problems (such as getting a necklace into a jar), on the way in which they categorize objects and on the first stages of language acquisition.

Much of the argument is based on a reanalysis of well-known phenomena. For example, the authors dwell at length on the familiar observation (originally Piaget's) of the 'A not B' error: babies who see an adult hiding an object in one place (A) and then later in another place (B) will go on looking for the object at $A$ even when they have just closely watched the adult put it in B.

According to the authors, babies make this particular mistake because they have formed a hypothesis that "the object will be where it appeared before" and arrive at this hypothesis on the basis of experiences such as dropping a toy out of their cot and not seeing it again until it has been tidied up and put back where it was originally.

This particular argument is typical of the book. It is ingenious and amusing and it could be right. But the authors offer no evidence for it. They do throw doubt (quite rightly, in my view) on one competing theory - that the error is due to the limitations in the children's ability to remember the sequence of events. Yet they fail to test, or even consider how to test, their own hypothesis even though it is, it seems to me, eminently testable.

Given the authors' willingness to offer a new view of babies' intellectual achievements, their unwillingness to find a way of testing it is ironic — after all, the book's main purpose is to persuade us how well young children set about testing their own hypotheses. The nearest they come to offering a direct test is in their account at the end of the book of their own work on language acquisition and on children's success in solving means-ends problems, in categorization tasks where they have to work out what has happened to an object they can no longer see ("object permanence").

Their research reveals specificity in the connections between different aspects of language acquisition and children's performance in different cognitive tasks. For example, they have shown a strong relationship between children's use of words denoting success and failure and their abili- ty to solve means-ends problems and a similarly close connection between their learning of words to do with appearance and disappearance and their success in object-permanence problems. No such connection was found across these two categories, however.

This is good research with genuinely interesting results, but it does not get near to establishing that these changes happen because babies test and abandon unsuccessful hypotheses and then form new ones.

We are left with a lively and entertaining book that will make us think again about children's intellectual development but will in the end convince no one. The authors will have to find some direct way of investigating how children form and abandon hypotheses if they want their fellow developmental psychologists to give up on one view and to espouse a completely different one.

Peter Bryant is in the Department of Experimental Psychology, University of Oxford, South Parks Road, Oxford OX1 3UD, UK.

\section{At a glance}

Excellent $t+x+$ Good $x+x$ Fair $x+$ Poor

\section{Quantum Mechanics in Chemistry}

by Jack Simons and Jeff Nichols

Oxford University Press: 1977. Pp. 612.

$£ 48.50, \$ 70$

Good books on quantum mechanics in chemistry are always welcome. This book contains the standard wavefunction and orbital material with many examples. Angular momentum theory, determinants, configuration interaction, molecular rotation and vibration, and time-dependent processes (including a good introduction to scattering) are all clearly introduced. There is a section on quantitative methods, introducing the Hartree-Fock method and basis sets. The authors' expertise in more advanced methodology such as MCSCF and response theories appears in the last chapter. There is also a 125-page appendix.

This well-written text provides a good basis to standard quantum chemistry. But I have an important criticism. In the past four years, density functional theory has 'taken over' computational chemistry. Here it is given four pages only, written from a historical, out-of-date perspective. The theory should be given prominence in modern texts on quantum chemistry.

Nicholas C. Handy Department of Chemistry, University of Cambridge, Cambridge CB2 1EW, UK.

\begin{tabular}{lc}
\hline Range & $\star \star \star$ \\
\hline Depth & $\star \star \star$ \\
\hline Accuracy & $\star \star \star$ \\
\hline Up-to-dateness & $\star \star$ \\
\hline Accessibility & $\star \star \star$ \\
\hline Style & $\star \star \star \star$
\end{tabular}

Vertebrate Palaeontology, second edition

by Michael J. Benton

Chapman and Hall: 1997. Pp. 452. £75, \$110

(hbk); $£ 24.99, \$ 50$ (pbk)

Aiming to outline more than 500 taxonomic groups of living and fossil vertebrates in fewer than 400 pages of well-illustrated text is ambitious. Michael J. Benton has successfully updated and expanded the first edition (1990) to make it a more thorough introduction to the topic. For example, the new developments in the understanding of tetrapod and avian evolution are here, along with new illustrations, references from 1996, detailed discussion 'boxes' on topics such as the "birds of Las Hoyas" and "Permian burrowing dicynodonts of the Karoo", and new cladograms.

Sections on preservation, ecology, biomechanics, plate tectonics and theories of extinction are all necessary to help explain and interpret the peculiarly biased nature of the fossil record, especially to biologists without a palaeontological background. But these days many, if not most, students of vertebrate fossils have little idea about basic vertebrate zoology. They will need to supplement this book with a standard text on vertebrate zoology.

Douglas Palmer 31 Mawson Road, Cambridge CB1 2DZ, UK.

\begin{tabular}{lc}
\hline Range & $\star \star \star \star$ \\
\hline Depth & $\star \star \star$ \\
\hline Accuracy & $\star \star \star \star$ \\
\hline Up-to-dateness & $\star \star \star \star$ \\
\hline Accessibility & $\star \star \star \star$ \\
\hline Style & $\star \star \star \star$ \\
\hline
\end{tabular}

